\title{
VIOLENCIA CONTRA LA MUJER COMO MAL ENDÉMICO EN LA SOCIEDAD CONTEMPORÁNEA
}

\author{
Artenira da Silva e Silva ${ }^{1}$ \\ Almudena García Manso ${ }^{2}$ \\ Rossana Barros Pinheiro ${ }^{3}$
}

\section{Resumen}

La violencia patriarcal es uno de los males endémicos de la sociedad presente.

El origen del orden patriarcal está tan presente en la cultura, en la sociedad y en los paradigmas de pensamiento que se ha convertido en una normalidad. Normalidad que alimenta una violencia misógina o violencia contra la mujer. El descrédito hacia la mujer y el machismo, y el feminicidio son actos comunes que se convierten en enfermizos y endémicos. Este trabajo es una reflexión sobre cómo desde un orden político, económico y de poder hemos llegado a una sociedad donde su estructura se funda en la desigualdad de derechos entre hombres y mujeres, una fuerte desigualdad e inequidad que influye en la construcción de los valores sociales, jurídicos, económicos, emocionales y sanitarios, todos ellos fundados en la normalidad del patriarcado y por ello no exentos de ser una ramificación más de la violencia contra la mujer.

Palabras clave: violencia contra la mujer, machismo, patriarcado, feminidad, feminicidio.

\footnotetext{
${ }^{1} \mathrm{PhD} /$ Postdoctorado en la Facultad de Psicología de la Universidad de Oporto. Doctorado en Salud Pública por la Universidad Federal de Bahía. Profesora e investigadora en el Departamento de Salud Pública y del Programa de Post Graduación de Derecho y las Instituciones del Sistema de Justicia de la Universidad Federal de Maranhão. Investigador en el Observatorio Iberoamericano de la Salud y Ciudadanía, miembro del Centro de Estudios de Derecho constitucionales.E-mail: artenirasilva@hotmail.com

${ }^{2}$ Doctora en Sociología y profesora e investigadora en el Departamento de Ciencias de la Comunicación y Sociologia de la Facultad de Ciencias de la Comunicación, Universidad Rey Juan Carlos. Sus líneas actuales de investigacion se centran en la sociologia del género, la sociologia del cuerpo, sociologia de la sexualidade, inmigracion e intercambio cultural. Ha publicado en numerosas revistas científicas de impacto nacional e internacional, así como en multitud de capitulos de libros y libros. Es membro del grupo e investigacion de excelnecia methaodos.org y secretaria de la revista methaodos.revista de ciências sociales, también es membro del Observatorio Iberoamericano de Salud y Ciudadanía y de FLACSO España. Email: almudena.manso@urj.es ${ }^{3}$ Investigadora del Programa de Post Graduación de Derecho y las Instituciones del Sistema de Justicia de la Universidad Federal de Maranhão. Abogada. E-mail: rossana.barros@hotmail.com
} 


\title{
INTRODUCCIÓN
}

\begin{abstract}
"Y ahora nosotras dos, solitas como hemos quedado, ¿qué muerte más atroz no nos espera, dime, si, a despecho de la ley, desafiamos los edictos y el poder del tirano? Hay que acordarse, Antígona, que hemos nacido mujeres y que no podemos luchar contra hombres; además que estamos sujetas a gente más fuerte y que hay que obedecer estos mandatos y otros más duros todavía". Antígona, Sófocles.
\end{abstract}

El discurso social predominante sobre la violencia contra la mujer acontecida en los espacios de lo doméstico y lo emocional resalta únicamente la última expresión cruel y aniquiladora que no es otra que el asesinato u homicidio, algo que en gran medida se debe a la cultura de lo macabro y lo violento como espectáculo cuyo recorrido histórico se remonta a siglos atrás (Muchembled, 2010) y a la forma en que esta cultura queda remanente en la espectacularidad de la muerte distribuida y emitida por los medios de comunicación e información los cuales son a su vez agentes de socialización. El hecho de que una muerte sea espectáculo-noticia genera un sobre señalamiento que puede derivar en un efecto llamada, sea porque se presenta al perpetrador como protagonista mediático (Penalva, 2009; Carrión, 2008) sea porque en la mayoría de los casos no se hace referencia alguna al castigo o pena (Gutiérrez-Zornzona, Notario, Martínez-Vizcaíno, 2009) o bien sea por que aparece entre velado el verdadero daño social convirtiéndose en una noticia que suscita el morbo o la curiosidad propia de la prensa amarilla (Carrión, 2008).

El peligro de la invisibilidad de lo no dicho y silenciado deriva en que son las estrategias del poder, en el caso de la violencia contra la mujer el poder resulta ser el patriarcado como sistema estructural de desigualdad, diferencia y discriminación. Un sistema que distribuye de forma in ecuánime los espacios sociales de poder y diferenciación determinando otredades entre las que están las mujeres. Las otras.

La violencia contra las mujeres materializada en ocasiones como violencia de género -violencia ejercida a una persona por pertenecer a un género determinado- $y$ violencia machista -cuando la persona que ejerce la violencia considera a la víctima un ser inferior por el mero hecho de ser mujer-ha ido enunciándose en los medios de comunicación en estas dos últimas décadas como un problema social endémico dejando atrás su enunciación como problema meramente doméstico, familiar o íntimo.

Se ha ido extendiendo por su magnitud y realidad pues abarca todas las esferas sociales desde la laboral hasta la doméstica, íntima y sexual cuyo daño social no es únicamente la víctima sino toda la sociedad pues se empieza a convertir en alarma social de falta de seguridad sobre todo en contexto donde la violencia contra la mujer se considera una violencia general que erosiona la seguridad dando paso a una sociedad sumergida en el riesgo, uno de los miedos más recursivos en Occidente desde la década de los años 80 sobre todo en Europa y los Estados Unidos de América, la sociedad del riesgo (Beck, 2006) pasa de ser algo que se escapa de ser sometido 
por el sujeto humano pero que es provocado por unas tecnologías o por unas acciones a ser algo que él mismo ha creado socialmente y también se escapa de su poder pero social y culturalmente hablando.

Otro problema al que nos enfrentamos a la hora de abordar la violencia contra la mujer es cómo mide la realidad. Ésta es medida de manera desigual en función de la sociedad y cultura en la que se contextualice, al igual que el periodo histórico marca la visión de la realidad la normatividad-que deriva de las imposiciones por necesidad e interés que una sociedad impone a sus sujetos- también marca cómo es la realidad pasando a ser algo que no puede ser universalmente válido, cuyos significados son diversos según "la mirada social" desde la que se percibe y se le da significado generando unas acciones u otras, nunca idénticas y nunca homogéneas pues la sociedad es su conjunto es plural, no hay normas universales para medir la realidad e identificarla.

En este sentido nos encontramos frente al dilema de qué es la violencia contra la mujer y que actos, acciones y normas -entre otros rasgos- la compone. Para ello partimos de las tecnologías biopolíticas que la miden y la datan encontrándonos con que las tecnologías más generales son las policiales, legales y clínicas. Policiales en cuanto a la denuncia, legales en cuanto a la tipificación del delito y clínicas en cuanto al daño físico y el óbito. En las últimas décadas se han incorporado otras tecnologías de medición como son las psicológicas y psiquiátricas que se refieren al daño psicológico, emocional y psíquico infringido y las económicas que se materializan en los daños o pérdidas económicas así como las prestaciones y pensiones (Gallego, 2010).

Las tecnologías de medición policiales, jurídicas, clínicas, psicológicas y económicas cuantifican estadísticamente la violencia pero no por ello estas estadísticas son representativas ya que la violencia contra la mujer no sólo es la que tipifican estas tecnologías -algo en lo que no vamos a entrar en el presente texto puesto que la tipificación legal, policial y clínica no es internacional y cambia en función del país- Además estas tecnologías no recogen todos los casos de violencia que sí tipifican puesto que ni todos los casos son denunciados, judicializados o clínicamente datados además de que no toda violencia es tipificada como tal por estas tecnologías de medición invisibilizando otros tipos de violencia..

Estas tecnologías computan como violencia las denuncias cursadas, los juicios finalizados o iniciados Según el país y su marco jurídico-penal cuentan como casos de violencia contra la mujer los juicios iniciados o sólo los finalizados con condena, los finalizados sin condena no contabilizan en las estadísticas-, las condenas y sus tipos, los óbitos y las hospitalizaciones por lesión o partes forenses, así como los informes psicológicos por daños o lesión. En ocasiones incluyen los internamientos de las víctimas en casas de acogida y rehabilitación social, el número de personas que se acogen a tratamiento psicológico y social. Como vemos tecnologías que recogen números de los que nacen datos estadísticos que miden una realidad oculta, pues la violencia contra la mujer tiene forma de iceberg ya que muestra una pequeña fracción de su inmenso tamaño ya que una parte, la menos visible, está oculta debajo del agua. 
No apreciamos la violencia en su totalidad sino que nos centramos en la violencia normativa que no es otra que la enunciada por las instituciones y tecnologías de poder que conforman el sistema biopolítico (Foucault, 2010), dejamos a un lado lo más cotidiano, los actos, actitudes, comportamientos, lenguajes, estilos de vida, ideologías, etc., un día a día que se convierte en la trampa oculta tras lo cotidiano, lo tradicional y la costumbre. Es en este mundo de lo común y cotidiano donde entran en juego los micromachismos o microviolencias de género.

Conductas cotidianas e instrumentalidad de la violencia de género en los medios de comunicación de masas, en lo simbólico, en lo cultural, en lo emocional y sentimental y en lo folklórico, unas formas de violencia que de tan comunes y asimiladas se han hecho invisibles y por ello no cuantificadas puesto que en la mayoría de las ocasiones éstos actos, hechos y estilos de vida son extremadamente subjetivos (Llorente, 2014) subjetividad que queda en entredicho cunado estos actos llegan a ser cuantificados y convertidos en datos que sí se pueden medir y analizar de manera objetiva (Ferrer, Bosch, 2005, Molina, San Miguel, 2009).

Ahondando en la historia de la violencia contra la mujer de forma muy general ésta siempre se ha considerado como un asunto exclusivo de la mujer y no un problema social (Osborne, 2010).

Al no ser un asunto o problema de interés colectivo se convirtió intencionalmente invisible en todos sus efectos. La agresión quedaba impune y no era reconocida en ningún precepto normativo-legal salvo daños colaterales -en el caso de afectar a otro varón o a los hijos-. Esta situación que aún se mantiene en una gran parte de culturas y sociedades ha ido nítidamente cambiando en los "países desarrollados" aunque el cambio forme parte de lo políticamente correcto y de lo que se debe hacer para ser desarrollado (Zikek, 2009).

La historia de Europa tras el fin de los antiguos regímenes teocráticos, la Revolución Francesa, la constitución de la carta de los derechos humanos -en origen los derechos del hombre excluyendo a la mujer de cualquier derecho- el advenimiento de la Revolución Industrial y el desarrollo urbano ha ido visibilizando la violencia de la mujer por la necesidad del imperio del capital (Federici, 2012) al considerarla como elemento fundamental en el engranaje productivo como reproductora y mano de obra, aupada por el auge de los movimientos sufragistas y feministas (VV.AA, 2013) la mujer fue erigiéndose socialmente como sujeto. Una trascendencia incompleta -siguiendo la idea de inmanencia y trascendencia de Simonne de Beauvoir (2005)-pues los privilegios educativos y formativos no son paritarios hasta bien entrado el siglo XX, los profesionales quedan lejos de ser paritarios a pesar de la existencia de marcos normativos que se fundan en la discriminación positiva imponiendo la presencia de mujeres por cuotas en espacios de poder político, social y económico (Atencio, 2015).

Aun así la violencia contra la mujer -la misoginia- sigue persistiendo a modo de herencia histórica que parece no tener fin, ejemplo de ello lo tenemos en el repunte de víctimas que se vienen dando en esta última década en América Latina y en España tal y como nos indican las estadísticas del observatorio de conocimiento 
sobre Violencia de Género ${ }^{4}$. La violencia ejercida contra la mujer viene formando parte de los hechos cotidianos y de lo normal desde tiempos antiguos, una raíz tan profunda que es difícil de arrancar y que se dispersa a través del imaginario social colectivo llegando a agravarse de tal manera que el feminicidio queda impune en la mayor parte de los casos (Segato, 2013).

El término feminicidio nos retrotrae de forma directa a los sucesos que desde la década de los 80 y 90 siembran de víctimas ciertas partes del mundo y en concreto Ciudad Juárez, México. Un error típico de la falta de memoria histórica. Si bien es cierto es una palabra contemporánea pero que responde a una barbarie muy antigua, tan antigua que se pierde en el horizonte de los tiempos.

A mediados del siglo XX se viene abajo la naturalización e invisibilidad histórica de la antigua barbarie de la violencia contra las mujeres. Como si se tratara de un resurgir al unísono y de manera global los movimientos feministas y pro derechos humanos comienzan a denunciar los asesinatos y daños sistemáticos causados a mujeres por el mero hecho de ser mujeres. La envergadura que fue tomando este fenómeno de denuncia y crítica no tardó en influir en el mundo académico el cual buscaba nuevas conceptualizaciones y acepciones más acordes a la situación - una violencia sistemática y fuera del periodo de guerras y conflictos latentes-, del mundo académico se pasó a la Comunidad Internacional la cual en 1993 en la Declaración de Naciones Unidas incorpora la Eliminación de la Violencia contra las Mujeres, así como la convención sobre Eliminación de todas las formas de Discriminación contra las Mujeres (CEDAW) de 1979 activa su protocolo Facultativo en 1999. Estos acontecimientos fueron un gran paso para el reconocimiento de los derechos de las mujeres como derechos humanos (Atencio, 2015).

El final del siglo XX estaba marcado por el derrumbe de varios mitos que marcarían el inicio del segundo milenio. Uno de esos mitos era que la violencia contra la mujer no sólo se ejercía en épocas de guerra o conflictos bélicos -en todas las guerras la mujer siempre ha sido la víctima civil por excelencia, ya no sólo como botín de guerra sino como ensañamiento y humillación para con los derrotados (Nash, 2003)-sino que la violencia contra la mujer se mostraba tal y como ha sido y tal y como es: estructural y sistémica. Otro de los grandes mitos que han caído en este inicio del milenio es el de creer que por qué existen leyes que defienden a la mujer y por el avance de los derechos civiles y humanos la mujer iba a conseguir la paridad y el reconocimiento igualitario. Algo que dista mucho de ser una realidad a nivel internacional.

${ }^{4}$ OBSERVATÓRIOVIOLENCIA.ORG. Disponible em:<http://observatorioviolencia.org/>. Acceso em 13 mai 2016. vol.12, no. 01, Rio de Janeiro, 2019.pp. 144170 


\section{FEMINICIDIO: UN TÉRMINO CONTEMPORÁNEO PARA UN ANTIGUO HORROR}

La violencia contra la mujer no es un fenómeno nuevo puesto que está fundado en un terror muy antiguo que es el miedo a que el otro -en este caso la mujer- pueda ejercer el poder. En el momento mismo en el que se crean unas leyes que regulan la reproducción y la posesión (Engels, 2008) se funda la diferencia entre unos -varones- y otros -mujeres- recayendo en unos el poder y las esferas públicas y en otras la reproducción de la especie, las tareas domésticas y la supeditación a los intereses del poder (Bourdieu, 2003).

Pero retomando el tema del feminicidio como la máxima y global expresión de la violencia contra las mujeres tenemos que pensar qué es y qué no es el feminicidio, un término que nace en América Latina en la década de los 80 concretamente en grupos organizados de mujeres de República Dominicana va extendiéndose hasta que en los años noventa la teórica feminista y antropóloga Marcela Lagarde introdujo dicho término en la Academia Mexicana así como Ana Carcero y Monserrat Sagot tradujeron el término del inglés Femicidio (Atencio, 2015).

Feminicidio o femicidio es un término que adquiere significados diferentes según el país o continente en el que se enuncie pero que viene a mostrar una realidad histórica que no es otra que a misoginia y el ensañamiento contra la mujer. El feminicidio va más allá del derecho elemental de vivir libres de violencia, puesto que en estas últimas tres décadas estamos viviendo un recrudecimiento de la violencia a gran escala y de manera generalizada, se centra en la violencia sistemática, endémica y general contra las mujeres sin más motivo que el de ser mujeres.

Además femicidio o feminicidio toma otras dimensiones en contextos no eurocéntricos, aunque Europa no está libre de femicidios pues la muerte de mujeres en manos de hombres por el hecho de ser mujeres así como la violencia machista va en incremento sin atisbos de frenarse es en el resto del mundo donde el término adquiere la dimensión pandémica.

El por qué en el resto del mundo el feminicidio adquiere una dimensión completamente diferente estriba en su propia herencia histórica y lo que es peor la herencia adquirida como países coloniales, su situación de país colonia los dejaba en el desamparo del gobierno satélite. Sin entrar en detalles sobre el colonialismo debemos dejar claro que éste fue dejando una huella de desigualdad, diferenciación, expropiación y usurpación no sólo de los bienes y las riquezas -sean estas naturales o no- de esos países sino la invasión, intromisión e imposición de una cultura que no era la suya. El gobierno satélite o títere no funcionaba nada más que en beneficio de los que estaban allende los mares y no en beneficio de la población colonizada. Su situación como sujetos de derechos dejaba mucho que desear. Si no era la inquisición la que actuaba como biopolítica del indígena o autóctono era el gobierno de los virreinatos el que hacía del indígena una otredad, un desigual o un impío, salvaje, etc., (Federici, 
2012). Si a esta otredad, la del indiano, indígena, autóctono, etc., añadimos la otredad de ser mujer la desigualdad se incrementa y surgen las dobles y triples discriminaciones. Ser mujer e indígena era y es una sobre exposición a la violencia.

No podemos olvidar que la gran parte de los países que han sido sometidos a la colonización o invasión colonial son países ricos en recursos naturales, un problema a añadir la expropiación, explotación y extracción de esos recursos. Tampoco debe caer en el olvido las guerras y luchas coloniales por el territorio, este último punto es fundamental para comprender las dinámicas de violencia en esos territorios donde desde la invasión han sido asediados y no han conocido largos tiempos de paz, tranquilidad o ausencia de conflicto. El "hombre blanco" cuando marchó -si es que se llegó a marchar- dejó todo sumido bajo el mando de guerrillas, luchas, revueltas y levantamientos sin pensar en cómo se iba a restaurar el país. Ya sean por guerras coloniales, por acuerdos o por desgaste el colonialismo casi extinto ha dejado una fuerte huella en esos países donde el feminicidio toma una dimensión diferente a la de la vieja Europa y otros países de cultura europea -Australia y algunos puntos de Estados Unidos.

Es este fenómeno de intrusión colonial el que demarca una construcción de otredad que se quedaría en el imaginario social colectivo para siempre como sujetos de inferioridad o discriminación. A esta afirmación tan taxativa hay que incluir el Darwinismo social que prevaleció durante la mitad del siglo XIX y principios del XX eclosionando en nacionalismos y en atrocidades contra los diferentes materializadas en genocidios y etnocidios.

Desde esta óptica no eurocéntrica el feminicidio no adquiere el mismo significado ni la misma dimensión que en esos "mundos desarrollados" donde la violencia contra la mujer se da pero se la intenta ocultar con la irreal igualdad de derechos.

El Feminicidio como máxima expresión de la violencia contra la mujer terminológicamente es polisémico, complejo y plural en significados, es una categoría transversal, transcultural, transdisciplinaria, transpolítica, transcontextual y transjurídica, pues no puede adquirir un único significado ni un único contexto en su tratamiento y datación. El Feminicidio como término acogiéndose al significado de homicidio, término que procede del latín homicidium - homo, hombre, cuyo genitivo se forma con el radical abreviado hom (o) tiene como radical inicial del nominativo fémina, mujer cuyo genitivo es fémina e, sin presentar alargamiento silábico. Siendo impecable la composición del término (Atencio, 2015:21).

Aun con todo el término no se ajusta a una única descripción, significado ni significante sino que está sujeto a la contextualidad y la transversalidad de la realidad que representa: "En castellano femicidio es una voz homóloga a homicidio y solo significa homicidio de mujeres. Por eso, para diferenciarlo, preferí la vos feminicidio y denominar así al conjunto de violaciones de los derechos humanos de las mujeres que contienen los crímenes y las desapariciones de mujeres y que, estos fuesen identificados como crímenes de lesa humanidad" (Lagarde, 


\section{1:18-19)}

Para comprender el porqué de la inclusión del feminicidio en este trabajo hay que entender las múltiples formas de la violencia contra la mujer y ésta es la máxima expresión, es el último acto de violencia extrema pues no está acompañada de manera única por el óbito o la muerte de las víctimas sino que está acompañada de la impunidad de los hechos, de los desórdenes que este hecho genera a nivel social, emocional y cultural, está acompañada de cómo es considerada a la mujer en los espacios públicos y en los privados, muestra mucho más allá que la muerte, muestra la cultura de la violencia en su estado más puro, pues en ocasiones el feminicidio no es un hecho que sea la muerte de la mujer sino que está acompañado por tortura, violación, vejación, ensañamiento y exposición pública o abandono de los restos generando una situación social difícil de manejar en contextos machistas pues pueden provocar un efecto imitatorio o efecto llamada más que provocar repulsa e indignación.

Casos como los de las violaciones múltiples en la India han generado revueltas y cambios legales e incluso han generado todo un movimiento social de mujeres, así como los feminicidios de Ciudad Juárez (México) que asolaron toda una sociedad y generaron un movimiento de lucha, reivindicación y llamamiento al orden público que se tradujo en cambios legales -sin demasiado éxito pues un gran porcentaje de casos siguen sin resolver y son muchas las que siguen desapareciendo- y últimamente van expandiéndose a otros países de América donde asociaciones de mujeres comienzan a reivindicar sus derechos y denunciar la falta de seguimiento jurídico y policial de los casos como son los casos de Argentina y Bolivia.

Parece ser que en algunos puntos del globo ser mujer es ser sinónimo de víctima, algo que no nos es nuevo pero que con el advenimiento de la globalización, los medios de comunicación de masas y la sociedad de la información y las comunicaciones es más visible y se puede divulgar. Debemos indicar que ser mujer como sinónimo de víctima lo es también en el resto de países, aquellos cuyas constituciones, legislaciones y códigos penales recogen la violencia contra la mujer como un delito o pena, algo que además está mal visto por la sociedad, países donde el maltratador es considerado como un criminal o un enfermo, países donde se han desplegado campañas de concienciación, proyectos de reinserción, políticas sociales de protección de las víctimas, etc., pero que no han podido hacer nada contra el crecimiento o mantenimiento del número de víctimas de la violencia contra la mujer -incluyendo los daños colaterales como son los hijos y los familiares cercanos-.

El feminicidio es el extremo de un continuo de terror anti femenino que incluye una gran cantidad de formas de abuso verbal y físico como violación, tortura, esclavitud -sexual, doméstica o económica- incesto y abuso sexual infantil intrafamiliar, maltrato físico y emocional, hostigamiento sexual -acoso telefónico, callejero, en Internet, en el trabajo en la escuela o centro formativo, etc.,-- mutilación genital o mutilación corporal, esterilización y operaciones ginecológicas innecesarias -histerectomías- heterosexualidad forzada, maternidad forzada -sea por abuso sexual, obligación por parte de los padres o esposo así como la criminalización y 
prohibición de métodos anticonceptivos- negación de alimentos, cirugías cosméticas forzadas o inducidas, psicocirugías, sobre exposición a trastornos de la alimentación por obligación -bulimia y anorexia-, obligatoriedad del trabajo doméstico, cuidado de niños y ancianos, obligación a la soltería por cuidados domésticos o familiares, matrimonios forzados y concertados sin consentimiento de la mujer, matrimonio infantil, maltrato psicológico, humillación, vejación y hostigamiento psicológico y social, entre otras acciones o formas de terrorismo contra la mujer (Russell y Radford, 2006)

La tercera apreciación es afirmar que existe feminicidio cuando existe impunidad jurídica, algo que no es del todo cierto aunque sí afecte la impunidad al igual que afectaría en los países "desarrollados" es una afirmación que está prefigurada por la falsa idea de que en los países de Europa y semejantes no existen delitos de este calibre que queden impunes, algo que no es cierto, muchos de estos delitos quedan impunes amparados por intereses que se escapan a la lógica de la rectitud legal, jurídica y penal, la corrupción es un mal endémico que está presente en todos los espacios de poder y en todos y cada uno de los contextos sociales.

La cuarta apreciación es la de calificar a todos los asesinatos de mujeres como feminicidios, un error recurrente en los medios de comunicación de masas pero que no es cierto pues muchos de los homicidios de mujeres no se han acometido por la razón de su pertenencia a un género o sexo determinado. No todos los asesinatos de mujeres son feminicidios.

Como quinta apreciación tenemos que indicar que no todas las formas de violencia extrema son feminicidios pues feminicidio es la pérdida de la vida de la mujer.

La última apreciación a este respecto es concerniente a que feminicidio no es violencia de género sobre todo en el espacio legal español tras la aplicación de la Ley Integral de Violencia de Género se limita a las relaciones de pareja o ex pareja. En este sentido esta ley queda completamente obsoleta desde su enunciación y puesta en vigor pues la violencia de género es estructural y se da fuera del entorno y contexto sentimental abarcando todos los espacios, escenarios y relaciones sociales. Fuera del marco normativo español feminicidio y violencia de género no son antagónico sino más bien lo contrario son complementarios.

Feminicidio es la evolución de un concepto que nace de un anglicismo femicidie pero que se desarrolla en América Latina y otros contextos otrora colonias. Es pues la herencia histórica la que marca el destino de las otredades, de aquellas que a ojos de todos son otras, diferentes, distintas y desiguales y por ello vulnerables y expuestas a la violencia y la exclusión (Young, 2012).

Ante el panorama más desolador y fatal de la violencia contra las mujeres no podemos olvidar explicar el origen la denominada trampa del patriarcado, sistema que utiliza a la mujer en base a sus necesidades como objeto y no como sujeto, un sistema que pretende normalizar su dominación (Gallego, 2010). 


\section{EL PATRIARCADO COMO SISTEMA QUE INSTITUCIONALIZA LA VIOLENCIA CONTRA LA MUJER}

"En muchos ámbitos, aún hoy, la dominación masculina está bien asegurada para transitar sin justificación alguna: ella se contesta con ser, en el modo de la evidencia” (Bourdieu, 1990: 116).

La violencia ejercida contra la mujer es un tipo de agresión encubierta por la cultura patriarcal la cual legitima la creencia de la posición superior del varón frente a la posición inferior de la mujer en los espacios sociales, sobre todo en los espacios de poder (Bourdieu, 2003)

Una de las definiciones de violencia contra las mujeres que mayor aceptación ha tenido es la ofrecida por Naciones Unidas y que la define como "todo acto de violencia sexista que tiene como resultado posible o real un daño físico o psíquico, incluidas las amenazas, la coerción o la privación arbitraria de libertad, ya sea que ocurra en la vida pública o en la privada” (ONU, 1994)

Bajo esta definición la violencia contra las mujeres, ya sea esta violencia de género, violencia machista, violencia doméstica, violencia familiar o violencia sexista se define como coacción física, psíquica o sexual sobre las mujeres con el objetivo claro de influir en su voluntad y obligar al sujeto a actuar en base a esa imposición.

La violencia en este sentido adopta diferentes formas ya sean daños físicos, verbales, psíquicos, sexuales, sociales, económicos, simbólicos, informativos, etc., En definitiva maneras de coacción y daño ejercidos de manera sutil o explícita desde tiempos antiguos.

La historia de la violencia de contra las mujeres va conexa a la historia del patriarcado. No hay un referente claro de cuando surge el patriarcado como estructura de poder pues muchas son las referencias que datan su existencia a los pequeños grupos sociales prehistóricos concretamente en la etapa lítica (Sanahuya, 2002). Aun así se continúa insistiendo en la idea que Engels expuso en su obra El origen de la familia, la propiedad privada y el estado (2008) que no es otra que el origen del patriarcado se remonta a las primeras civilizaciones estamentales, jurídicamente normativas y sedimentarias - de ahí la concepción de la familia y el territorio como propiedad-

"El patriarcado comienza a darse en la época histórica, con el régimen monogámico, como una manera de sometimiento de un sexo (el femenino) al otro (el masculino) (Engles, 2008: 253).

El patriarcado ha sido uno de los conceptos recurrentes a la hora de explicar o dar a entender las diferencias sociales y de las sociedades a lo largo de la historia. No es hasta finales de la década de los años sesenta del pasado siglo cuando el feminismo comienza la búsqueda de teorías que permitan un abordaje diferente al análisis sobre la subordinación de las mujeres, intentando explicar la desigualdad existente entre los sexos alejadas de la idea de patriarcado como sistema de poder basado únicamente en la productividad y la familia. Es en este 
punto en el que cuestionan la idea clásica -defendida desde el siglo XVII- y que se centra en la idea del "derecho del padre" cuando se refiere al sistema que históricamente deriva de las legislaciones griega y romana, legislaciones y sociedades en las que el padre era el cabeza de familia de una unidad doméstica, el cual ejercía todo el poder legal, económico y social sobre los demás miembros de esa unidad doméstica.

Este uso tradicional hacía que el patriarcado solamente tuviera vigencia desde la antigüedad hasta la concesión de los derechos civiles a las mujeres hecho que aconteció en el siglo XIX. Este uso que se le daba al concepto de patriarcado distorsionaba la realidad histórica ya que "la dominación patriarcal de los cabezas de familia es anterior a la antigüedad clásica y, por otro lado, en el siglo XIX, la dominación masculina dentro de la familia cambia pero no finaliza" (Lerner, 1990: 340)

Uno de los primeros intentos por redefinir el concepto y significado del sistema patriarcal fue el dado por Kate Millet en Sexual Politics (1970). Millet considera al patriarcado a modo de institución política, una red de estructuras sociales cuyo nexo común y articulador no es otro que el cariz político de las relaciones entre los sexos.

Es así como Millet da un nuevo sentido al concepto rompiendo con la idea clásica y tradicional del cabeza de familia. Para la autora de Sexual Politics el patriarcado se desliga de la idea del derecho connatural que poseen los padres para ser un derecho y poder que poseen los hombres en general y los maridos en particular. Derechos destinados a estructurar las relaciones de poder y dominio sobre las mujeres con un fin que no es otro que el de garantizar a los hombres el ejercicio de control sobre estas. En el marco de esta conceptualización lanza un mensaje que hoy en día sigue siendo uno de los lemas de algunos feminismos "lo personal es político". Este lema infirió en los feminismos de tal manera que comprendieron cómo "las relaciones entre los sexos debían ser consideradas como una de las dimensiones fundamentales de la sociedad y, en consecuencia, había que incluirlas en la teoría social y la política” (Sanahuya, 2002: 17).

Esta definición de patriarcado hace referencia a la apropiación por parte de los hombres de la capacidad sexual y reproductiva de las mujeres y es ampliada por Lerner (1990) quien vincula patriarcado con cambios en la organización del parentesco y en las relaciones económicas, con a la aparición de burocracias civiles y religiosas ligadas en periodos de tiempo al desarrollo de los primeros estados y al surgimiento de cosmogonías que incluían una gran cantidad de divinidades masculinas.

Por otro lado Morace (1993) apunta a que el nacimiento del patriarcado estuvo acompañado de una cadena o serie de coerciones ininterrumpida que implicaban el uso de la fuerza y la presencia de especialistas ejército, sacerdotes, jueces, etc.,-- para ejercitarla. Morace afirma la existencia de sociedades "matrísticas" anteriores al patriarcado pero que fueron erradicadas y subyugadas por la imposición del poder masculino. En este sentido el igualitarismo es sustituido por la competencia imponiéndose la omnipotencia y omnipresencia de la coerción, la violencia y el control. 
Esta autora define las sociedades matrísticas como sociedades asamblearias, de discurso, negociación y paz pero que caen ante la privación de los derechos políticos para gran parte de su población -mujeres, niños, extranjeros, etc.,- y por el surgir de los cargos políticos que se convierten en hereditarios por vía masculina y retribuidos siendo éste el momento en el que aparece la propiedad privada.

Carol Pateman (1995) señala que el patriarcado como sistema de poder político sigue en plena vigencia aunque su definición continua siendo ambigua y confusa. Pateman ve necesaria la distinción de tres formas de patriarcado con el fin de evitar ambigüedades. Formas que aun siendo diferentes no se excluyen entre sí. La primera forma es la del pensamiento patriarcal tradicional el cual asimila todas las relaciones de poder al derecho paterno o regla del padre -mencionada anteriormente por la cual se abre el debate del agotamiento conceptual del patriarcado-, un pensamiento acompañado de toda una mitología sobre cómo surge la propiedad privada a partir del nacimiento de la familia dejando en vigor la tesis de Engels. La segunda forma es la de la teoría del patriarcado clásico la cual sostiene que el poder patriarcal y el poder político no son análogos sino idénticos. Los hijos nacen bajo la sujeción de sus padres y por ello bajo la sujeción política. Es en este sentido cuando se considera el derecho político como natural y no convencional siendo el poder político paternal el origen del poder.

La tercera forma es la del patriarcado moderno que parte de la transformación a finales del siglo XVII -el periodo de la acumulación del capital- de la teoría clásica del patriarcado mediante las aportaciones de los teóricos del contrato social. Este es el patriarcado moderno que es denominado "fraternal y contractual" y especulador de la sociedad civil capitalista.

El concepto de patriarcado tuvo una gran acogida en los Estados Unidos sobre todo durante la década de los setenta, poco después se afianzo en Europa y no fue hasta mediados de la década de los ochenta cuando se extiende a otros países de Asia, América latina y África pues en el caso de los países que estaban en proceso de lucha por su independencia colonial su aceptación tardía se pudo deber "al temor que la lucha contra el patriarcado quebrantara la solidaridad de las mujeres de izquierdas con sus hombres en las guerras de liberación contra el colonialismo" (Rivera, 1994: 74-75).

Todos estos estudios sobre patriarcado centraron su atención en exponer cómo el derecho de los hombres estructura las relaciones de poder sobre el cuerpo de las mujeres, centrando su atención en la subordinación de las mujeres y considerando la reproducción y la sexualidad femenina como las claves del patriarcado. De ahí la importancia de la sexualidad en los procesos de violencia contra la mujer.

A la categoría patriarcado se le atribuye todo lo negativo de la experiencia pasada y presente de las mujeres ya que se presenta como "algo ahistórico, eterno, invisible e inmutable" (Lerner, 1990:67).

Pero sigue siendo un término que está en plena vigencia y que hace clara referencia a la sujeción de las mujeres demostrando el derecho político que detentan los varones. 
Una vez perfilado el contexto social en el que los sujetos han vivido, viven y vivirán no nos cabe duda alguna que este sistema de poder -el patriarcado-construye la visión del mundo y de las realidades sociales. Además dirige, crea y marca los valores, las pautas, la moral, las conductas, las normas y la distribución del poder material, político y social de la sociedad.

La socialización en su amplio sentido se lleva a cabo en contextos sociales, no lejos de una colectividad, influida por ésta y por los grupos sociales inmediatos y de referencia para con el sujeto en vías de socialización.

La socialización que viene a ser el proceso por el cual el sujeto aprende a ser sujeto social está completamente influido por el patriarcado pues es este el sistema social imperante, de ahí que las normas culturales, sociales y políticas que rijan en ese sistema pasaran a formar parte del sujeto y de la forma en la que ve y considera realidad y sociedad influyendo en las actitudes, conductas, formas de ser y pensar.

Reflexionar en torno a la violencia de género y el patriarcado obliga a exponer los pasos por los que el sujeto llega a construir su identidad sobre todo en cuanto a las esferas de interacción entre el sujeto y la violencia como problema estructural y no coyuntural. La construcción de la identidad se lleva a cabo de manera par al proceso de socialización, ésta se inicia con el nacimiento del sujeto dura a lo largo de toda la vida y se funda en las relaciones que se establecen entre el individuo y los demás grupos sociales -sean estos primarios o secundariosUn proyecto de vida en el que cada individuo va diferenciando entre quién es, quién quiere ser y quién es para los demás o el proceso de la construcción del yo hacia el vosotros y nosotros procesos que van cambiando según cambia la sociedad y los agentes de socialización.

Dependiendo de qué variables sociológicas se den en ese momento en el contexto sociocultural, los grupos se irán constituyendo en agentes socializadores para cada rol social. Edad, estatus económico, género y etnia por ejemplo, como variables a considerar marcan el recorrido en la conformación y construcción identitaria, la socialización no es inocua a las variables sociales.

Al proceso de socialización y las instituciones que hacen posible ese proceso -familia, escuela, grupos de pares, institución religiosa, institución política, etc.,- hay que añadir las variables socio demográficas que determinan al sujeto y que lo contextualizan en la sociedad es por lo que el género, la edad, la raza, la etnia, la procedencia, el idioma, la religión, el nivel cultural, el nivel económico y la ideología entre otras variables afectan en la conformación de la identidad. Pero estas variables no se dan solas sino que se dan bajo el influjo de un contexto social predominante que en el caso que nos compete no es otro que el sistema patriarcal.

Entre todas esas variables la que más poder enunciativo tiene es la de género. Término que nace de la clínica en la década de los años 20 acuñado como gender por Money (Preciado, 2008) en su intento por definir un sexo determinado a los bebés intersexuales y que ha marcado la historia de la división socio-sexual ya existente encrudeciendo más si cabe las diferencias y desigualdades. En el momento que nace la etiqueta la diferencia es 
mayor y ésta diferencia se puede enunciar, se puede reiterar, se puede expandir y como no institucionalizarse como tecnología de poder.

El género como tal es de reciente creación pero su significado no, la diferenciación entre machos y hembras por cultura y sociedad es tan antigua como lo es el patriarcado, pero no es hasta el momento en el que éste se institucionaliza cuando pasa a ser más poderoso y más diferenciador.

En el momento que los sujetos son adscritos a un género determinado, regido por el patrón hetero normativo del patriarcado que no es otro que el sistema sexo/género binario -masculino/femenino-, el sujeto ya con su género -por imposición social- recibe un bagaje cultural distinto en todas y cada una de las esferas o espacios sociales en los que transite desde su nacimiento y a lo largo de todo su proceso de socialización y resocialización. En todas y cada una de esas esferas sociales se haya codificada las normas del patriarcado, los valores y la cosmovisión que hace que la diferencia termine siendo desigualdad, que se perciba a la mujer como otra, un sujeto infravalorado e infra valorable, un objeto más que un sujeto, ofreciendo un desigual reparto de poderes y espacios sociales. El privado para a ser espacio de la mujer, el público es el espacio del hombre, recayendo de esta forma todo el poder fáctico y real sobre él (Pérez Fernández, 2009).

En estos procesos de socialización y conformación de la identidad, las interrelaciones que se efectúan entre el sujeto y la sociedad están plagadas de añadidos, sujeciones e intenciones que dirigen o re dirige la vida de los sujetos al son de las necesidades, intereses o deseos de quien o quienes detentan el poder. El sistema, en este caso ya definido rotundamente como patriarcal, marca unas tecnologías de poder que como bien define Michel Foucault (2005a;2005b y 2005c; 2010) empujan al sujeto social a su sujeción por la biopolítica, tecnologías de poder que se enmarcan perfectamente en los intereses de la dominación masculina, una biopolítica (Foucault, opcit), tecnopolítica (Winner, 1987), infopolítica (Lash, 2005) y psicopolítica (Byung-Chul, 2014) que siguen las pautas de la otredad femenina, un proceso de othering (Young, 2012) que se entremezcla con los logros civiles, legales, políticos y económicos conseguidos.

Es en los procesos de aprendizaje y socialización donde se podría ejercer fuerza en y agrietar el sistema patriarcal, sólo con la coeducación, concienciación, erradicación de valores machistas e inclusión de valores e ideas igualitarias se podría ir abriendo una brecha en el Iceberg de la violencia contra la mujer.

Hago mención al iceberg de la violencia contra la mujer puesto que ésta se asemeja a la forma de un iceberg. Posee un lado visible que es el más pequeño y un lado invisible que está sumergido y por ello escondido pero que es el que mayor tamaño tiene. Una metáfora de la sociedad patriarcal y de la violencia contra la mujer, sólo se ve una mínima parte de la totalidad, la cual está escondida y sumergida. 


\section{LA TRAMPA DE LA VIOLENCIA INVISIBLE}

La trampa de la violencia invisible es lo desconocido dentro de lo conocido, "un elemento capaz de generar esas consecuencias negativas sin ser consciente de que se puede producir" (Llorente, 2014:16)

Se llega a naturalizar y a convertir como cotidiano aquellos factores que conllevan a la desigualdad, en este caso a la violencia y a las expresiones de la misma, ya sean estas violencia fáctica, psicológica, simbólica, económica, social o política sin olvidarnos de la violencia cultural entre otras.

Según Llorente (2014) todas las acciones que conlleva el concepto de trampa han estado presente de las siguientes maneras:

Se busca siempre atrapar a alguien -en este caso a las mujeres- dentro de un contexto o de unas referencias que delimiten el significado de los acontecimientos y las acciones realizadas. Todo ello se hace en interés de los hombres y siempre buscando las ventajas, los beneficios y los privilegios, lo que nos muestra cómo son los varones los que realizan la trampa y las mujeres las que caen en ella. Un proceso en el que se rompen las leyes, las normas o las pautas anteriores, aunque son estas leyes y normas las que dan pié a la existencia de la trampa.

El juego de las trampas provoca una deuda al generar beneficios para unos a costa de prejuicios paro otras, deuda que se demora en el pago y se deja a sabiendas para un futuro problema en otra acción tramposa, puesto que no se tiene la pretensión de resolver en el futuro, sino que por el contrario, se hace del futuro un problema al darse cabida una situación que se afronta sin ánimo de resolverse. "Por eso la desigualdad vive más en un pasado prolongado que en un acercamiento al futuro"(Llorente, 2014: 18).

Las trampas no deberían ser lo normal. Cualquier intento de lograr algo de manera ilegal o de manera canallesca no debería ser aceptable como forma de articular la convivencia. Al usar una trampa para obtener una posición ventajosa debería de establecerse un sistema de prácticas y acciones que impidieron o coaccionaran dichos actos, la violencia fáctica y la psicológica así como aquella que atenta contra la igualdad de oportunidades de manera jurídica sí están regladas bajo el paraguas de la ley, el delito y la pena, pero las trampas no son sólo los "grandes y punibles" machismos o violencias visibilizadas sino micro trampas, micro violencias o micromachismos que conviven y se dan en lo cultural, en lo cotidiano y que están normalizadas en las conductas del día a día.

Pero no debemos olvidarnos que lo normal es en sí una trampa, puesto que lo normal es aquello que es presentado como apropiado para un determinado fin, algo esperado o consecuente con unos factores concretos. En este sentido hablar de lo normal en el marco del sistema patriarcal es ejecutar la trampa. Primero necesitaremos las herramientas para después convertir lo normal en lo excepcional. La coeducación y la visibilización, la sensibilizazción y la culturización parecen ser las armas más adecuadas para la lucha contra todos los tipos de 
violencia contra la mujer -las visibles y las invisibles-.

Al visibilizar la violencia de género ya sea a través de los medios de comunicación o bien por su empuje legal se consigue un doble objetivo desvelar todo aquello que permanece oculto y ver el origen de la situación. Para ello hemos dividido en dos dimensiones a considerar: la manera en cómo actúa y la forma en cómo se da la violencia contra las mujeres. Dimensiones que conforman un todo sistémico de la violencia la cual afecta de forma total a todos y todas los sujetos humanos.

Entre esas dos dimensiones hay que destacar que lo primero que se visibiliza es la violencia física o fáctica cuyo final es en ocasiones la muerte de la mujer.

Dentro de la violencia fáctica y física debemos señalar que se ubica la violencia sexual y las agresiones sexuales denunciadas, las que no están denunciadas pasan al siguiente nivel o dimensión de la violencia.

La violencia sexual se sale de los parámetros del placer para entrar en los parámetros de la humillación, la territorialidad, la dominación, la ira y la demostración de victoria tal y como acontecía en las guerras y conflictos armados, siendo la violación un acto bélico más que un acto que busca el placer sexual aunque también ha sido botín de guerra o ha sido utilizada como esclava sexual a modo de agravio comparativo ante el contrincante (Nash, 2003), la violación como agresión en el cuerpo posee una lectura que en ocasiones se traduce como territorio a ocupar (Segato, 2013). Desde antiguo la violación ha sido y es una de las agresiones y expresiones de violencia más vergonzosa y que se ubica en el imaginario social colectivo cuyo significado social tiene al sexo como estrategia de dominación y subyugación, la violación tiene un significado socio-cultural muy pesado pues consta de irrumpir en la voluntad sexual de una persona siendo sometida y haciendo una intromisión en lo socialmente considerado como más íntimo y privado.

El segundo nivel que viene a estar representado por la violencia oculta e invisibilizada está compuesta por un tipo de actos, acciones y comportamientos violentos que quedan invisibilizados -sea consciente o inconscientemente- y que por lo común se dan en espacios cotidianos, domésticos, familiares, interpersonales y emocionales. En este sentido podemos hablar de la violencia psicológica, de las dinámicas interpersonales violentas -discusiones, enfados, broncas, peleas, etc.,-, de la violencia económica, de la violencia política, de la violencia laboral, de la violencia sanitara o en materia de salud, de la violencia educativa entre otras violencias que se hayan inmersas en las dinámicas del día a día en las mujeres en diferentes instituciones y organizaciones o esferas sociales.

Otros de los tipos de violencia oculta e invisibilizada son la violencia verbal, la violencia simbólica, la violencia cultural y los micromachismos.

La base de estas dos dimensiones se extiende en forma de pautas culturales difícilmente descalificadas como sexistas debido a su carácter cotidiano y por tratarse de actitudes, comportamientos o rasgos extendidos por 
cualquier sociedad y/o colectivo social. Pero "el hecho de que un comportamiento constituya un rasgo cultural no le otorga el valor de que sea inherente, invariable o insustituible"(Martínez Pérez, 2008). Un fenómeno social tiene la categoría de hecho cultural puesto que no es identificado como hecho dañino o peligroso y por ello susceptible de ser modificado, ni siquiera es visto como un problema y menos aún como un conflicto. Las diferencias entre sexo y género son imprescindibles para comprender que los roles asociados a lo masculino y lo femenino son meras construcciones culturales y sociales, en las que se introduce la linealidad normativa entre sexo, género y orientación sexual.

Barry, Bacon y Child (1995) llevaron a cabo un estudio en el que confirman que el patriarcado se extiende a lo largo de toda la historia de la humanidad como especie. Estos tres autores tras analizar los valores transmitidos y aprendidos en los procesos de socialización en diferentes cultural, llegaron a la conclusión de que el juicio de valor "valerse de uno mismo" es un aprendizaje inculcado a los niños varones en el $85 \%$ de las sociedades a estudio, por otro lado el juicio de valor "cuidado" es atribuido a las mujeres en el $82 \%$ de las culturas analizadas. En este sentido se puede contemplar como en todos los procesos de socialización analizados las variables obediencia y responsabilidad son atribuidos al género femenino, mientras que el logro aparece como una variable claramente de atribución masculina. Desde la perspectiva dominante y tras el análisis del estudio arriba indicado podemos subrayar que el patriarcado como modelo y sistema sociocultural ha triunfado a lo largo de los siglos, un éxito que se debe en gran medida a su invisibilización y apropiación de las oportunidades de la otra mitad de la humanidad, de las mujeres, lo femenino.

También podríamos afirmar que el proceso pudo darse a la contra y que la ocultación o invisibilidad fue el requisito previo para que el patriarcado se implantara y se expandiera. El proceso de mantener oculta a una parte de la realidad y la historia tuvo que ver con el proceso de separación de espacios y tiempos, recursos y derechos así como oportunidades y, como no, con el proceso de atribución de roles y poderes entre lo identificado o identificable como femenino y masculino.

De toda esta deriva, la constitución de las atribuciones de género, la construcción del patriarcado y la distribución -desigual- de recursos y poderes, deviene el hecho de que las agresiones y el ejercicio de la violencia contra las mujeres -por razón de género o sexo- deban ser entendidas dentro de un contexto socio cultural, muchos de esos ejercicios de violencia adquieren connotaciones y significados muy diferentes en función de la sociedad y cultura en la que se den, pero no por ello dejan de ser deplorables.

La violencia de género no entiende de edades, géneros, clases sociales ni niveles económicos, estatus cultural o razas, se ejerce en la dimensión de la visibilidad y en la de la invisibilidad, en el caso de la invisibilidad es el que nos ocupa a continuación, la micro forma de violencia o micro terrorismos como muchas y muchos los designan y definen. La trampa de lo cotidiano está en el micromachismo. 


\section{EL DÍA A DÍA DE UNA MUJER ES UN CAMPO DE BATALLA}

Anteriormente hemos criticado cómo el concepto género es una de las tecnologías de poder más dañinas. Eso con lo que algunos se identifican y otros identifican a los demás no es más que una categoría de diferenciación que contiene las tres D: diferencia, desigualdad y discriminación.

La categoría género es transversal, atraviesa a toda la sociedad pero realmente no es la etiqueta de género la que atraviesa esa sociedad, tal y como acabamos de afirmar sino los ojos que la mira, la mirada social que ha asimilado la categoría-etiqueta de género es la que la identifica, la enuncia y la socializa. Sin la mirada social del género el género en sí mismo no existiría, no habría cabida para esta categoría sin la sociedad que la traduce, la enuncia y la impone pues es la mirada la que dispone pero antes de ello ha tenido que existir y articularse esa categoría con un fin específico, todo lo que es nombrado en la sociedad posee un significado y un significante intencional, nada se escapa a la diferenciación y clasificación.

El etiquetado social desde sus orígenes residía en el capital o en la productividad de los cuerpos-sujetos, desde el lítico hasta nuestros días podríamos decir que el patriarcado se funda en tres premisas: producción, reproducción y diferencia. Premisas que traducidas en la materia que nos competía a entender la violencia contra las mujeres se cumplen en todas las etapas de la humanidad, marcando los destinos de todas las mujeres. La cultura se apropió de este triángulo adornando la producción, reproducción y diferencia de diversos procesos culturales como son la maternidad como forma de ser de la mujer, la nutricia, los cuidados y el amor romántico, los sentimientos y la dulzura como formas del ser y del estar propias de la mujer. Si miramos la inmensa cantidad de escritos literarios, políticos, históricos y filosóficos escritos desde la antigüedad la mujer está marcada por la diferencia siendo uno de sus rasgos más comunes el de la debilidad y la concupiscencia, la maternidad y el cuidado, el placer y la inocencia entre otros rasgos, "humores" - desde la óptica platónica-, naturalezas y demás calificativos descriptivos de la mujer como una eterna menor o un ser inferior al varón (Pomeroy, 1991).

El capital ha cambiado como concepto social, ya no divide clases sociales sino que deshumaniza individuos. Los expulsa del proletariado, los desarraiga del sentimiento de pertenencia a una clase social, los etiqueta como clase media y los empuja hacia una espiral de consumo-producción-consumo de la que no salen. En este entramado de capital-consumo-producción entra la variable género como una variable a añadir a la precariedad de las personas pues además de ser un sujeto del capital de la precariedad es más vulnerable por su "capacidad" reproductiva siendo víctima de sistemas de producción mediocres, con una capacidad de gasto inferior pero enrolada en una cultura de la belleza, sin contar que la mayor parte de las tareas productivas de gran responsabilidad y poder le son vetadas o en el caso de conseguirlas siempre caerá la duda sobre su cualificación, capacidad. El doble esfuerzo o la doble demostración de su capacidad productiva viene siendo uno de los rasgos 
característicos del sistema productivo en perspectiva de género femenino, así como la cultura-consumo de la belleza es dominio de su capacidad de gasto influyendo directamente en su condición como sujeto del sistema consumo-producción-consumo.

Si el sujeto del siglo XXI está abordado por la globalización, el cambio climático, las guerras tácticas internacionales, el terrorismo invisible pero real, la superpoblación mal repartida, el consumismo y el gasto como cotidianeidad y necesidad social, la precarización de la vida, el control de los datos y la vida "datificada" o "infoxicada", el dominio de los medios de comunicación y la influencia de estos sobre las decisiones de los sujetos, la infravaloración de la ciencia, la cultura y la academia, el empobrecimiento de la calidad de los sistemas educativos, el recrudecimiento de las leyes contra la libertad de expresión y la inculcación de estilos de vida hedonistas, individualistas y masivos hacen que este sujeto vaya introduciéndose en las fauces de la precariedad sin solución a corto plazo. Pues el capital nos quiere dóciles, sumisos y adictos a la espiral del consumo, no hay que pensar ni revelarte pues el castigo es severo y el estigma social de estar en el margen del sistema es más que un hecho constatable.

La acomodación y la resiliencia son las respuestas más generales ante este panorama pues no existe demasiada creatividad para salir de la precariedad que el sistema marca, sólo la lucha tenaz y solidaria, algo de lo que las mujeres saben bastante, podría servir como punto de inicio. Esto no significa que no existan movimientos de lucha, reivindicación y acción contra este sistema pero en ocasiones no tienen la univocidad que sí tuvo el movimiento sufragista femenino en todo el mundo.

Volviendo al panorama y la relación que posee con la violencia debemos de indicar que el capitalismo contemporáneo no sólo contrae formas precarias de producción, la producción en sistema de semi esclavitud de determinados países es realizada por los más vulnerables del sistema que son los niños, los jóvenes y las mujeres, sino que conlleva a sistemas de violencia productiva o capitalismo gore (Valencia, 2013) no sólo en cuanto a los negocios ilícitos y que generan multitud de víctimas y daños colaterales en la población de gran magnitud sino a cómo a través de la demostración de la violencia contra las mujeres grupos o personas se empoderan en esos sistemas de capital gore que están íntimamente ligados al capitalismo neo liberal. La violencia contra las más vulnerables y precarias se capitaliza y se rentabiliza en los negocios y movimientos económicos que se dan en el capitalismo gore, pues la muerte de las mujeres, su explotación laboral, sexual, económica y física se rentabilizan y forman parte de ese capital gore.

La segunda forma viene de la mano del amor romántico como método de explotación y método de sumisión (Esteban, 2011). El amor romántico como construcción biopolítica de los géneros y sobre todo de la mujer-feminidad como la víctima del dolor de amor y la feliz amada, dualismos que provocan tensiones en el desarrollo normal y equilibrado de una persona, pues el tener que vivir pensando en conseguir el príncipe azul y 
encontrarte con una rana es muy frustrante y desolador sobre todo para aquellas mujeres que se vieron abocadas a pensar y a volcar toda su vida en ser la princesa que bese la rana, haciendo de la vida un sueño inexistente que produce desazón, dolor y ruptura de expectativas cuanto menos, lo peor es cuando el amor romántico conduce a comportamientos violentos como el suicidio por amor, el asesinato por celos o el crimen pasional.

La siguiente forma muy ligada a la primera, pues sigue el patrón clásico de la feminidad como el objeto y no el sujeto, es la del culto a la belleza normativa y estereotipada. Los cánones de belleza han ido cambiando en función del contexto socio-histórico y cultural en concreto, desde la década de los años 50 del siglo XX en adelante el canon de belleza se vio atravesado por el negocio de la estética, la cosmética, la moda y la quirúrgica convirtiéndose en un mayor negocio-pues la belleza femenina siempre ha sido uno de los negocios más fructíferos desde tiempos inmemorables-, el canon de belleza que se fue imponiendo era el de la mujer femenina por antonomasia, cambiando en función de las modas y sobre todo en función de la erotización de los medios de comunicación pero siempre encaminada a someter a la mujer a disciplinas de cambio y adecuación a gustos ajenos a los suyos, gustos que en ocasiones había interiorizado desde la infancia como lo que debe ser o lo que tienes que ser de mayor para atraer a un hombre, siempre está el gustar a los demás y luego si cabe lugar gustarte a ti misma, pura mercantilización del sujeto pues el cuerpo, la identidad y los estilos de vida giran en torno a esa belleza que es consumida y que es adquirida por un precio determinado (Russell, 2008). La belleza en sí no es violencia pero la imposición de una belleza sí, sobre todo la instauración de sistema de belleza mercantilizado que además de imponer empobrece e incrementa el consumo-producción-consumo de los sujetos precarizándolos más. La belleza para los demás es la imposición de una violencia sistémica pues está dentro del sistema social y del sistema de diferenciación de géneros y sexos, la masculinidad tiene sus cánones de belleza que han cambiado en estas últimas décadas y se están mercantilizando y la feminidad posee sus cánones mercantilizados de manera más impositiva, imperativa y discriminante pues ser mujer y bella o estar acorde a los cánones de la erotización masculina es sinónimo de éxito algo que poco a poco se está desplazando a la masculinidad.

La pecera de goma como violencia contra las mujeres es un término que creemos conveniente como sustituto del techo de cristal o como concepto que lo acompañe. El techo de cristal aunque parezca mentira permite a las mujeres de forma desigual y precaria crear su microclima en la última escala socio-laboral a la que pueden acceder por su condición de género, pues en muchos sistemas socio-laborales la mujer está vetada en cuanto a persona que puede acceder por su cualificación y dotes a un puesto superior al de sus compañeros varones. Este tipo de jerarquías hacen que la mujer pueda ver como los demás acceden a mejoras mientras ella se queda en su puesto o lugar, puede ver pero no acceder. Para explicar lo que hemos comentado antes "el techo de cristal al menos te permite crear un micro clima" no es una aseveración positiva más bien es una crítica feroz pues ella se quedará en ese microclima, estancada y encallada mientras que en igualdad de condiciones habría 
ascendido o no, pero habría tenido la oportunidad que nunca se le dio.

Ahora bien la pecera de goma es la situación más contemporánea en los contextos socio-laborales el porqué es muy sencillo y responde a la precariedad y vulnerabilidad de todos los trabajadores encarnizada en los más expuestos que en el caso que nos compete es el de la mujer. En una pecera de goma ni siquiera puedes hacer o crear tu microclima, pues la goma no permite que la luz que necesitas para vivir entre de forma correcta generando un clima tóxico donde no puedes crear ningún micro clima, no puedes hacer nada. Pecera porque al igual que un pez no tienes un techo pero nunca saltarás más allá del borde de la pecera generando una frustración mayor. La situación de la mujer en el contexto socio-laboral se ha ido recrudeciendo desde la crisis mundial que venimos padeciendo desde mediados-finales de la década de los 2000, una crisis que es endémica y que no tiene vistas de acabarse pues es el paso a un nuevo sistema socio-económico y político aún muy difuso y aún indescriptible pero lo que sí tenemos claro de ese nuevo sistema es que el grado de desigualdad social y la brecha entre ricos y pobres se van agrandando cada vez más, que lo que otrora fue la clase media hoy en día está desapareciendo para convertirse en la clase social precaria.

Respecto a los problemas de salud de las mujeres ajenos a su capacidad reproductiva los más diagnosticados, al margen de las patologías comunes en ambos géneros, es la mirada de género a los trastornos psicológicos y psiquiátricos. El estilo de vida derivado de la doble carrera o la carga socio-cultural de los sistemas patriarcales generan un estrés mayor en mujeres que en hombres, ante estas situaciones las posologías y tratamientos que se dan por género marcan una clara narcotización y sobre medicación de ansiolíticos y antidepresivos en mujeres que en hombres, mientras a un varón le dicen que haga deporte a una mujer le recetan un ansiolítico, quizás este hecho nos pueda dar que pensar a la hora de tratar a la mujer como un sujeto farmacológico. La relación mujer depresión es muy larga en la historia de la cultura, arraigada en los mismos pilares de la cultura greco-latina y heredada en la cultura cristiana y católica, la mujer como sinónimo de culpa (García-Estébanez, 2008). Tendríamos mucho que hablar sobre la violencia sanitaria de la mujer pero no abundaremos en ello en este texto.

Culturalmente el fracaso matrimonial se considera según estilos de vida, cosmovisiones y contextos socio-culturales un fraude o un problema a resolver el cual la única solución es la continuidad del matrimonio aún en situaciones de abusos, violencia y extorsión hacia la pareja, amenazándola de muerte, violación, agresión a los hijos o demás familiares. Son éstos los casos que derivan en la típica frase lapidaria y por desgracia reveladora de realidades: "la maté porque era mía". Pues estos tipos de matrimonios fundados en la violencia, resiliencia, abusos y posesión tienen un alto índice de finalizar en asesinato o crimen contra la mujer o sus hijos.

Haciendo referencia a esto último, al daño contra los hijos mencionar que otra forma de violencia es la que vamos a denominar como violencia de daños colaterales, un eufemismo que encubre una dura realidad que es vol.12, no. 01, Rio de Janeiro, 2019. pp. 144170 
el uso de la violencia contra los/as hijos/as u otros familiares y/ amigos/as a modo de venganza cuya única finalidad es la de hacer daño al cónyuge.

Sin entrar en más detalles pasamos a la violencia psicológica que hoy en día a tomado un cariz de extensión global pues los medios de comunicación y las tecnologías de la información han permitido que ese acoso sea global, intenso en tiempo y en número de mensajes, multimedia pues puede estar apoyado en montajes fotográficos y vídeos, multicanal ya que el acoso puede ser emitido desde diversos canales a la vez con ánimo de un mayor hostigamiento. Pero será y es psicológico por no dejar huellas físicas -salvo en la somatización del estrés producido y el suicidio inducido por éste- pero es exactamente igual de dañino que las demás formas.

La violencia institucional o administrativa es otra de las formas de violencia que más se da y que en ocasiones más impunemente queda. En este sentido la violencia no la ejerce la pareja o un hombre con vinculación emocional sino que es ejercida desde las instituciones de poder sean estas jurídicas, policiales o médicas. Abundando en este tipo de violencia institucional o administrativa debemos señalar cómo en determinados países quedan impunes asesinatos masivos de mujeres y feminicidios, violaciones, trata de mujeres y violencia doméstica o violencia contra la mujer en el contexto conyugal. Sea por descomposición de los sistemas de arbitraje u obsolescencia de las leyes que tipifican estos delitos, sea por exoneración de los victimarios o victimización de los mismos -auto victimización o vistimización institucional- lo que sí es cierto que estos sistemas están bajo el amparo del patriarcado, son tecnologías de biopoder muy ligadas a la comprensión de la mujer como un objeto y no como un sujeto.

La objetividad, neutralidad y empatía con la problemática social deberían de ser los baluartes institucionales. Otro problema a añadir a este tipo de violencia es la lentitud de los procesos y la falta de medios para las víctimas en dichos procesos dejándolas al amparo de sí mismas ante una situación de riesgo inminente que en ocasiones no es más que la crónica de una muerte anunciada.

La violencia económica y el difícil acceso al mercado laboral remunerado es la última forma de violencia que vamos a mencionar. Es lógico entender que la libertad y autonomía económica es algo que mejoraría la vida de millones de mujeres que han de sobrevivir bajo el amparo de sus varones o el amparo de la misericordia. El desarrollo autónomo como sujetos económicos les permite salir de situaciones de pobreza, analfabetismo -otro tipo de violencia es la educativa- y desamparo. En ocasiones es la educación la que juega un papel fundamental para salir de esta forma de violencia, el acceso a una formación permite a mujeres de contextos en desarrollo acceder a un mejor puesto de trabajo y con ello a poseer una autonomía económica. 


\section{BREVE REFLEXIÓN A MODO DE CONCLUSIÓN}

El problema debe ser visibilizado, consiguiendo con ello un doble objetivo frenar las actitudes, comportamientos y actos que se consideran cotidianos pero que lastran el bienestar y la igualdad entre hombres y mujeres.

La violencia contra las mujeres es un mal endémico, sistémico y de difícil erradicación pues en vez de aminorarse parece ser que se está recrudeciendo siendo un mal internacional y global que afecta a todos los hemisferios indistintamente pero de manera desigual, no podemos olvidar que la violencia colonial hizo demasiado daño en el hemisferio sur, dejando una reciente cultura de la opresión, misoginia, violencia y racismo que se ha materializado en procesos de guerras civiles, tribales, étnicas y dictaduras que han marcado la historia del siglo XX y de estas últimas décadas en aquellos territorios que en épocas pasadas formaban parte del imperialismo eurocéntrico.

El contexto internacional en materia económica, política y social no es el más adecuado para aminorar esta problemática, el cambio social ante el que nos encontramos la anteriormente denominada precarización de la humanidad no ayuda en demasía a la independencia económica y profesional de las mujeres.

El ver cómo la violencia contra las mujeres no es homogénea ni unívoca, es metamórfica y multiforma pasando de ser considerada como un mal doméstico y privado a un mal social, pues deteriora el sentido social y su bienestar. La mayor expresión de este deterioro se materializa en los feminicidios y en los daños colaterales que estos provocan pues el asesinato de una mujer no es un hecho que únicamente afecta a la víctima sino que afecta a todos los niveles, a nivel familiar, a nivel institucional y a nivel cultural siendo su normalización cultural uno de los principales problemas ante los que nos encontramos.

Precisamos ver la violencia como un iceberg y visualizarlo y tratarlo como algo que es un problema mayor e implica a muchas otras esferas sociales de las que se ve incluyendo las esferas más públicas e institucionales.

El cómo erradicar la violencia contra las mujeres no posee una pronta fórmula o respuesta pues son muchos los matices que hay que considerar desde los culturales, contextuales, sociales, económicos, religiosos hasta los institucionales, climatológicos. Lo que sí es cierto es que este mal deriva de una falta de coeducación, educación y aculturización en los valores de igualdad, paridad entre hombres y mujeres seguidos de unas acciones legislativas, médicas e institucionales -fuerzas de seguridad y del orden-empáticas con la sociedad que tratan.

Consideramos otras formas de violencia contra las mujeres que no se han explicitado en este texto pero que forman parte de la contemporaneidad y del citado capitalismo gore como es la migración forzosa, sea esta por motivos económicos o por problemas sociales, bélicos u otros motivos como los desastres naturales. En el caso de 
la migración transfronteriza el género es transversal a otras variables que hacen de esta migración una violencia más acusada, entre esas variables está la de la edad, el nivel cultural y la etnia (Hernández-Hernández, 2015).

A modo de broche final a este texto y como cierre o reflexión el tema no es baladí, la violencia contra las mujeres que tan históricamente arraigada está debe ir solventándose con la caída de los valores patriarcales y estableciéndose un sistema paritario e igualador en derechos y deberes para todos los sexos y géneros. Además se debería de repensar el significado del género, su sesgo como categoría diferenciadora no ayuda en demasía a la erradicación de las situaciones de vulnerabilidad, abuso y desigualdad.

\title{
VIOLENCE AGAINST WOMEN AS AN ENDEMIC DISEASE IN CONTEMPORARY SOCIETY
}

\begin{abstract}
Patriarchal violence is one of the endemic illnesses of present society. The origin of the patriarchal order is so present in culture, in society and in paradigms of thought that it has become a normality. Normality that fuels misogynist violence or violence against women. Discredit towards women, machism, and femicides are common acts that have become unhealthy and endemic in society now a days. This work is a reflection on how from a political, economic and power order we have reached a society where its structure is based on the inequality of rights between men and women. This work presentes thes trong inequality that influences the construction of social, legal, economic, emotional and sanitary values, all based on the normality of patriarchy and therefore not exempt from being a further ramification of violence against women.
\end{abstract}

Keywords:violence against women, chauvinism, patriarchy, feminism, femicide.

\section{BIBLIOGRAFÍA}

BARRY, H; BACON, M.K, CHILD, I.L. "Una revisión transcultural de algunas diferencias de sexo en la socialización" en Velasco, H. (coord.). Lecturas de antropología social y cultural. Madrid: UNED, 1995. 
BEAUVOIR, S. El segundo sexo. Madrid: Cátedra, 2005.

BECK, U. La sociedad del riesgo: Hacia una nueva modernidad. Madrid: Paidós. 2006.

BOURDIEU, P. La dominación masculina. Madrid: Anagrama, 2003.

BYUNG-CHUL, H. Psicopolítica. Barcelona: Herder, 2014.

ENGELS, F. El origen de la familia, la propiedad privada y el estado. Madrid: Alianza Editorial, 2008.

ESTEBAN, M.L. Crítica del pensamiento amoroso. Barcelona: Bellaterra, 2011.

FERRER PÉREZ, V; BOSCH FIOL, E. Introduciendo la perspectiva de género en la investigación sobre violencia de género. En Anales de psicología. Vol. 21, n¹, pp. 1-10, 2005.

FOUCAULT, M. Historia de la sexualidad I: La voluntad del saber. Madrid: Siglo XXI, 2005.

FOUCAULT, M. Historia de la sexualidad II: El uso de los placeres. Madrid: siglo XXI, 2005.

FOUCAULT, M .Historia de la sexualidad III: El cuidado de sí. Madrid: Siglo XXI, 2005.

FOUCAULT, M. Vigilary Castigar. Madrid: Siglo XXI: 2010.

GALLEGO AYALA, J. Eva devuelve la costilla. Nuevo estado de conciencia de las mujeres. Barcelona: Icaria, 2010.

GARCÍA MESEGUER, A. ¿Es sexista la lengua española? Una investigación sobre el género gramatical. Barcelona: Paidós, 1994.

GARCÍA-ESTÉBANEZ, F. Contra Eva. Barcelona: Melusina, 2008.

HERNÁNDEZ-HERNÁNDEZ, O. Niñas migrantes: relatos de menores mexicanas repatriadas de Estados vol.12, no. 01, Rio de Janeiro, 2019. pp. 144170 
Unidos. En methaodos.revista de ciencias sociales, 1 (3). 122-133, 2005. doi:10.17502/m.rcs.v3i1.76.

LAGARDE, M. Claves feministas en torno al feminicidio, Construcción teórica, política y jurídica, In: FERGOSO, R.L y BEJARANO, C (eds). Feminicidio en América Latina. México DF: UNAM, 2011.

LASH, S. Crítica de la Información. Buenos Aires: Amorrurtu, 2005.

LERNER, G. La creación del patriarcado. Madrid: Crítica, 1990.

LLORENTE ACOSTA, M. Tú haz la comida que yo cuelgo los cuadros. Madrid: Crítica, 2014.

MARTÍNEZ BENLLOCH, I; BONILLA CAMPOS, A. Sistema sexo/género, identidades y construcción de la subjetividad. Valencia: Universidad de Valencia, 2000.

MARTÍNEZ GARCÍA, J. A. El lenguaje de género y el género lingüístico. Oviedo: Universidad de Oviedo, 2008.

MARTÍNEZ PÉREZ, A. El vuelo de la alondra: violencia sistémica y familiar. En Sociedad y Utopía. Revista de Ciencias Sociales, n³1, 2008, pp. 125-140.

MILLET, K. Política sexual. Madrid: Cátedra, 2010.

MOLINA, E; SAN MIGUEL, N (coord.). Nuevas líneas de investigación en género y desarrollo. Madrid: Universidad Autónoma de Madrid, 2009.

MORACE, S. Origine donna: dal matrismo al patriarcato. Roma: Prospettiva Edizioni, 1993.

NASH, M. Las mujeres y las guerras: el papel de las mujeres en las guerras de la Edad Antigua a la Contemporánea. Madrid: Icaria, 2003.

ONU (1994). Declaración sobre la eliminación de la violencia contra la mujer. Resolución de la Asamblea

General, 20-12.1993 (Doc. G.A. Res. 48/104), 1994. Disponible en http://www.unhchr.ch/huridocda/huridoca.nsf/\%28symbol\%29/a.res.48.104.sp?opendocument. [Consultado el 2 de mayo de 2013]. 
ONU. Declaración sobre la eliminación de la violencia contra la mujer. Resolución de la Asamblea General, 20-
12.1993
(Doc.
G.A. Res.
48/104),
1994.
Disponible
en

http://www.unhchr.ch/huridocda/huridoca.nsf/\%28symbol\%29/a.res.48.104.sp?opendocument. [Consultado el 2 de mayo de 2013]

PENALVA, C. El tratamiento de la violencia en los medios de comunicación. En Alternativas. Cuadernos de trabajo social, $n^{\circ}$ 10,2002, pp.395-412.

PÉREZ FERNÁNDEZ, I. Espacio, identidad y género. Sevilla: Arcibel, 2009.

POMEROY. S. Diosas, rameras, esposas y esclavas. Mujeres en la antigüedad clásica. Madrid: AKAL, 1991.

RIVERA, M. Nombrar el mundo en femenino. Pensamientos de las mujeres y teoría feminista. Barcelona: Icaria, 1994.

RUSSELL HOCHSCHILD, A. La mercantilización de la vida íntima. Apuntes de la casa y el trabajo. Madrid: Katz, 2008.

RUSSELL, D.E y RADFORD, J (Eds). Feminicidio. La política de asesinatos de las mujeres. México D.F: UNAM, 2006.

SEGATO, R. La escritura en el cuerpo de las mujeres asesinadas en Ciudad Juárez. México DF: Universidad del Claustro de Sor Juana, 2013.

VV:AA. Sociología y género. Madrid: Tecnos, 2013.

YOUNG, J. El vértigo de la modernidad tardía. Buenos Aires: DIDOT, 2012.

Trabalho enviado em 21 de agosto de 2017

Aceito em 12 de janeiro de 2019 